\title{
Anti-Inflammatory Properties of Fructo-Oligosaccharides in a Calf Lung Infection Model and in Mannheimia haemolytica-Infected Airway Epithelial Cells
}

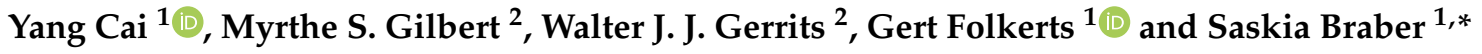 \\ 1 Division of Pharmacology, Utrecht Institute for Pharmaceutical Sciences, Faculty of Science, \\ Utrecht University, 3584 CG Utrecht, The Netherlands; y.cai@uu.nl (Y.C.); G.Folkerts@uu.nl (G.F.) \\ 2 Animal Nutrition Group, Wageningen University, 6708 WD Wageningen, The Netherlands: \\ myrthe.gilbert@wur.nl (M.S.G.); walter.gerrits@wur.nl (W.J.J.G.) \\ * Correspondence: S.Braber@uu.nl; Tel.: +31-(0)6-2248-3913
}

check for updates

Citation: Cai, Y.; Gilbert, M.S.; Gerrits, W.J.J.; Folkerts, G.; Braber, S. Anti-Inflammatory Properties of Fructo-Oligosaccharides in a Calf Lung Infection Model and in Mannheimia haemolytica-Infected Airway Epithelial Cells. Nutrients 2021, 13, 3514. https://doi.org/ $10.3390 /$ nu13103514

Academic Editor: David C. Nieman

Received: 13 August 2021

Accepted: 4 October 2021

Published: 6 October 2021

Publisher's Note: MDPI stays neutral with regard to jurisdictional claims in published maps and institutional affiliations.

Copyright: (c) 2021 by the authors. Licensee MDPI, Basel, Switzerland. This article is an open access article distributed under the terms and conditions of the Creative Commons Attribution (CC BY) license (https:/ / creativecommons.org/licenses/by/ $4.0 /)$.

\begin{abstract}
Emerging antimicrobial-resistant pathogens highlight the importance of developing novel interventions. Here, we investigated the anti-inflammatory properties of Fructo-oligosaccharides (FOS) in calf lung infections and in airway epithelial cells stimulated with pathogens, and/or bacterial components. During a natural exposure, 100 male calves were fed milk replacer with or without FOS for 8 weeks. Then, immune parameters and cytokine/chemokine levels in the bronchoalveolar lavage fluid (BALF) and blood were measured, and clinical scores were investigated. Calf primary bronchial epithelial cells (PBECs) and human airway epithelial cells (A549) were treated with Mannheimia haemolytica, lipopolysaccharides (LPS), and/or flagellin, with or without FOS pretreatment. Thereafter, the cytokine/chemokine levels and epithelial barrier function were examined. Relative to the control (naturally occurring lung infections), FOS-fed calves had greater macrophage numbers in BALF and lower interleukin (IL)-8, IL-6, and IL- $1 \beta$ concentrations in the BALF and blood. However, FOS did not affect the clinical scores. At slaughter, FOS-fed calves had a lower severity of lung lesions compared to the control. Ex vivo, FOS prevented M. haemolyticainduced epithelial barrier dysfunction. Moreover, FOS reduced M. haemolytica- and flagellin-induced (but not LPS-induced) IL-8, TNF- $\alpha$, and IL-6 release in PBECs and A549 cells. Overall, FOS had anti-inflammatory properties during the natural incidence of lung infections but had no effects on clinical symptoms.
\end{abstract}

Keywords: respiratory diseases; pneumonia; airway inflammation; animal model; non-digestible oligosaccharides; nutrition

\section{Introduction}

Lung infections are a particularly common destructive public health problem in both humans and livestock, associated with high morbidity, mortality, and costs [1-3]. When the defense of the respiratory system is impaired, pathogens quickly invade and colonize the epithelium of the lower respiratory tract, resulting in the development of lung infections [2]. Antibiotics are the main treatment for lung infections, but the emergence of bacterial resistance necessitates more extensive research on strategies to improve (lung) health, and thus reduce the use of antibiotics.

Calves are naturally prone to respiratory infections and are demonstrated to be a valuable animal model for studying lung infections in general, due to a high natural prevalence, easy-to-observe respiratory symptoms, and the continuous production of inflammatory mediators in the airways [2]. Moreover, various bacteria and viruses can cause respiratory diseases in calves, among which Mannheimia haemolytica is one of the major Gram-negative bacteria which cause lung infections [2,4]. Notably, the airway epithelium forms a complex physicochemical barrier to provide the first line of defense 
against inhaled pathogens [5]. However, M. haemolytica initiates strategies to impair the airway epithelial barrier to achieve invasion and colonization, including the induction of excessive inflammatory responses [6].

Non-digestible oligosaccharides (NDOs) have the potential to reduce respiratory diseases in human and murine species due to their prebiotic and immunomodulatory properties [7-9]. For instance, oral pectin-derived acidic oligosaccharides (pAOS) increased the bacterial clearance and reduced the tumor necrosis factor (TNF)- $\alpha$ release in mice with $P$. aeruginosa-induced lung infections [8]. Moreover, the NDO mixture containing fructo-oligosaccharides (FOS) and galacto-oligosaccharides (GOS) prevented (especially respiratory) infections during the first 6 months of age [9] and reduced the frequency of respiratory infections, fever, and antibiotics in the following two years in infants [10]. In addition, different NDOs, such as human milk oligosaccharides (HMOs), FOS and GOS, can also be absorbed into the systemic circulation after oral administration [11-14] and exert direct effects on the pathogens or host cells. There is some evidence that specific NDOs, such as HMO, GOS and FOS, can directly regulate the function and signaling of Toll-like receptors (TLRs) [15-17], which orchestrate the inflammatory response to lung infections in both humans and calves by recognizing exogenous pathogen- or endogenous danger-associated molecular patterns [2,18]. Therefore, NDOs, such as FOS, are attractive candidates in the (direct or indirect) prevention or decline of lung infections/inflammation.

Based on these findings, we hypothesized that FOS may alleviate lung infectioninduced inflammation in calves. Due to the possible presence of FOS in the systemic circulation after oral administration, we investigated whether FOS could affect the signaling of TLR4 and 5 and the subsequent inflammatory response in primary bronchial epithelial cells (PBECs), as well as whether they could restore the impaired epithelial barrier function induced by $M$. haemolytica.

\section{Materials and Methods}

\subsection{In Vivo Experiments}

\subsubsection{Animals and Experimental Design}

This experiment was conducted under the Dutch Law on Animal Experiments in accordance with EU Directive 2010/63 at the research facilities of the VanDrie Group (Scherpenzeel, The Netherlands) and was approved by the Animal Care and Use Committee of Wageningen University (AVD1040020185828, Wageningen, The Netherlands).

One hundred male Holstein Friesian calves aged 18 days $(43.2 \pm 0.33 \mathrm{~kg}$, means $\pm \mathrm{SEM})$ and of German origin were used and assigned randomly to 2 treatments. The control treatment ( $n=50$ calves) received the control milk replacer (MR). The FOS treatment ( $n=50$ calves) received $0.25 \%$ FOS (92\% purity based on dry matter, DP 2-8, Frutalose OFP, Sensus, The Netherlands) in the MR at the expense of lactose (Table 1). The experiment consisted of an experimental period (week 0-8) and a growing period (week 9-27). In the experimental period (week 0-8), FOS treatment was applied, and measurements were performed. After the experimental period (week 0-8), during the growing period (week 9-27), all calves received the same MR (control MR).

Table 1. Ingredient and nutrient composition of the experimental calf milk replacers.

\begin{tabular}{ccc}
\hline & Experimental Period & Growing Period \\
\hline Ingredient & $\mathbf{g} / \mathbf{k g}$ \\
\hline Lactose or fructo-oligosaccharides & 2.7 & \\
Lactose & 32.3 & 560 \\
Whey powder & 527 & 93 \\
Delactosed whey powder & 52 & 55 \\
Whey protein concentrate & 50 & 41 \\
Soy protein concentrate & 60 & \\
Soluble wheat protein & 50 & \\
\hline
\end{tabular}


Table 1. Cont.

\begin{tabular}{|c|c|c|}
\hline & Experimental Period & Growing Period \\
\hline Ingredient & \multicolumn{2}{|c|}{$\mathrm{g} / \mathrm{kg}$} \\
\hline Pea fiber & 3 & \\
\hline Extruded wheat flour & & 41 \\
\hline \multicolumn{3}{|l|}{ Fat } \\
\hline Lard & 43 & 48 \\
\hline Tallow & 68 & 77 \\
\hline Coconut oil & 54 & 34 \\
\hline Lecithin & 7.2 & 5 \\
\hline Emulsifier & 7.2 & 5 \\
\hline Premix & $10^{2}$ & $10^{3}$ \\
\hline Calcium formate & 9.7 & 10 \\
\hline Citric acid & 2.0 & 2 \\
\hline Sodium bicarbonate & 4.0 & 4 \\
\hline Mono ammonium phosphate & 3.5 & 2 \\
\hline Lysine & 9.8 & 8 \\
\hline Methionine & 2.4 & 3 \\
\hline Threonine & 1.3 & 2 \\
\hline Aroma $^{4}$ & 0.2 & \\
\hline Nutrient & \multicolumn{2}{|c|}{$\mathrm{g} / \mathrm{kg}$ of Dry Matter unless Noted } \\
\hline Dry matter, $\mathrm{g} / \mathrm{kg}$ & 975 & 976 \\
\hline Crude ash & 82 & 74 \\
\hline Crude protein, $\mathrm{N} \times 6.25$ & 231 & 191 \\
\hline Crude fat & 193 & 184 \\
\hline Lactose $^{5}$ & 453 & 455 \\
\hline Iron, ppm in dry matter & 48 & 10 \\
\hline
\end{tabular}

${ }^{1}$ In experimental period, calves received either lactose (control) or $2.7 \mathrm{~g} / \mathrm{kg}$ lactose was replaced with $92 \%$ pure FOS according to their allocated treatment. ${ }^{2}$ The premix in experimental period provided (per kg of experimental diet) CP, $0.7 \mathrm{~g}$; crude fat, $0.2 \mathrm{~g}$; starch, $5.1 \mathrm{~g}$; crude ash, $1.5 \mathrm{~g}$; calcium, $16.6 \mathrm{mg}$; phosphorus, $7.6 \mathrm{mg}$; sodium $0.7 \mathrm{mg}$; potassium, $7.3 \mathrm{mg}$; chloride, $13.1 \mathrm{mg}$; magnesium, $0.5 \mathrm{~g}$; iron, $37.2 \mathrm{mg}$; copper, $7.4 \mathrm{mg}$; zinc, $109 \mathrm{mg}$; manganese, $43 \mathrm{mg}$; selenium, $0.3 \mathrm{mg}$; iodide, $6.9 \mathrm{mg}$; sulfur, $84 \mathrm{mg}$; vitamin A, 25,011 IU; vitamin D3, $4002 \mathrm{IU}$; vitamin E, $142 \mathrm{IU}$; vitamin C, $0.3 \mathrm{~g}$; vitamin $\mathrm{K} 3,2.1 \mathrm{mg}$; vitamin B1, $8.2 \mathrm{mg}$; vitamin B2, $10.2 \mathrm{mg}$; vitamin B3, $34.9 \mathrm{mg}$; vitamin B5, $18.0 \mathrm{mg}$; vitamin B6, $9.4 \mathrm{mg}$; vitamin B12, $0.1 \mathrm{mg}$; biotin, $0.1 \mathrm{mg}$; choline, $0.4 \mathrm{~g}$; and folic acid, $0.7 \mathrm{mg} .{ }^{3}$ The premix in growing period provided (per kg of experimental diet) $\mathrm{CP}, 0.8 \mathrm{~g}$; crude fat, $0.1 \mathrm{~g}$; starch, $5.5 \mathrm{~g}$; crude ash, $1.3 \mathrm{~g}$; calcium, $17.0 \mathrm{mg}$; phosphorus, $8.1 \mathrm{mg}$; sodium, $0.8 \mathrm{mg}$; potassium, $7.8 \mathrm{mg}$; chloride, $13.2 \mathrm{mg}$; magnesium, $0.5 \mathrm{~g}$; iron, $0.3 \mathrm{mg}$; copper, $4.0 \mathrm{mg}$; zinc, $100 \mathrm{mg}$; manganese, $43 \mathrm{mg}$; selenium, $0.3 \mathrm{mg}$; iodide, $1.0 \mathrm{mg}$; sulfur, $78 \mathrm{mg}$; vitamin A, 25,000 IU; vitamin D3, $4000 \mathrm{IU}$; vitamin E, $100 \mathrm{IU}$; vitamin C, $0.1 \mathrm{~g}$; vitamin K3, $2.1 \mathrm{mg}$; vitamin B1, $8.2 \mathrm{mg}$; vitamin B2, $10.2 \mathrm{mg}$; vitamin B3, $34.8 \mathrm{mg}$; vitamin B5, $18.0 \mathrm{mg}$; vitamin B6, $6.3 \mathrm{mg}$; vitamin B12, $0.1 \mathrm{mg}$; biotin, $0.1 \mathrm{mg}$; choline, $0.4 \mathrm{~g}$; and folic acid, $0.7 \mathrm{mg}$. ${ }^{4}$ Aroma was purchased from LUCTAROM L, Lucta, Barcelona, Spain. ${ }^{5}$ Calculated contents of control MR.

During these two periods, all calves were naturally exposed to pathogens in the environment (natural incidence of disease where animals were not challenged). Individual antibiotic treatment was applied when required based on clinical signs of illness as assessed by the animal caretakers. The number of applied individual antibiotic treatments did not differ between the control and FOS groups ( $p>0.1 ; 10$ vs. 6 during the experimental period and 7 vs. 15 during the growing period). Group antibiotic treatment was applied equally to all groups if $10 \%$ of the calves had been treated within 5 days, or if $5 \%$ of the calves had become ill within $24 \mathrm{~h}$, or when the situation required group antibiotics in the expert judgement of a veterinarian.

The in vivo study described in this article was part of a large calf trial, including 300 calves randomly assigned to a control treatment, FOS treatment, and 4 other treatments with different (dietary) interventions (50 calves/treatment). In accordance with the purpose of this study, investigating the effect of oral FOS supplementation on lung infection, we reported here the results of the analyses of the control and FOS treatments in this large calf trial. 


\subsubsection{Housing and Diets}

Calves were housed in a mechanically ventilated indoor stable throughout the experiment. The climate guidelines included that, in the first 3 weeks, a minimum temperature of $15^{\circ} \mathrm{C}$ was maintained and heat canons were used when needed. Thereafter, ventilation rates were adjusted to maintain a maximum $\Delta \mathrm{T}$ of $5{ }^{\circ} \mathrm{C}$ compared to the outside temperature and a maximum relative humidity of $80 \%$. The ambient lighting consisted of natural lighting plus artificial lighting from 06:00 to 18:00 h. Calves were housed in pens $\left(9 \mathrm{~m}^{2}\right)$ containing wooden-slatted floors. In the first 6 weeks after arrival, individual housing was applied ( $1.2 \mathrm{~m}^{2} /$ calf) by placing stainless steel fences within the pens. After 6 weeks, the individual fencing was removed, and calves were housed in groups of 5 .

All calves were fed individually twice a day with MR according to a practical feeding scheme, in which MR increased progressively from 426 to $1300 \mathrm{~g} /$ day in the experimental period and from 1300 to $2711 \mathrm{~g} /$ day in the growing period. MR was mixed with warm water $\left(66^{\circ} \mathrm{C}\right)$ for $4 \mathrm{~min}$. Cold water was added and mixed to obtain a final concentration of $125 \mathrm{~g} / \mathrm{L}$. From week 21 onwards, the concentration was gradually increased to a maximum of $181 \mathrm{~g} / \mathrm{L}$ in week 27 . The reconstituted MR was supplied to the calves at a temperature of approximately $42{ }^{\circ} \mathrm{C}$. Calves were individually fed two equal MR meals at 06:00 and 16:00 $\mathrm{h}$. Individual MR feeding during group housing was assured by fixing calves in the headlock of the fence. Calves were allowed access to the MR for at least $15 \mathrm{~min}$. In addition, the ingredient and nutrient composition of MR diets are displayed in Table 1.

In addition to the MR, all calves received the same solid feed from 1 week after arrival and onwards. Solid feed was composed of chopped wheat straw and muesli and supplied at a ratio of 16:84 for 2 weeks and then at a ratio of 13:87. Muesli comprised corn, $412 \mathrm{~g} / \mathrm{kg}$; corn flakes, $200 \mathrm{~g} / \mathrm{kg}$; lupines, $195 \mathrm{~g} / \mathrm{kg}$; barley, $102 \mathrm{~g} / \mathrm{kg}$; molasses, $50 \mathrm{~g} / \mathrm{kg}$; vitaminmineral mix, $25 \mathrm{~g} / \mathrm{kg}$; urea, $6 \mathrm{~g} / \mathrm{kg}$; palm oil, $5 \mathrm{~g} / \mathrm{kg}$ and sodium-bicarbonate, $5 \mathrm{~g} / \mathrm{kg}$. Analyzed crude protein content was $140 \mathrm{~g} / \mathrm{kg}$ dry matter. Solid feed was supplied per pen and increased progressively from 174 to $984 \mathrm{~g} /$ day per calf in the experimental period and from 1020 to $2620 \mathrm{~g} /$ day in the growing period. Feeding levels of both MR and solid feed were equal between calves.

\subsubsection{Sample Collection and Measurements}

During the experimental period (week 0-8), clinical scores were weekly assessed for all calves (50 calves/treatment), while leukocyte parameters and cytokine/chemokine concentrations in blood and bronchoalveolar lavage fluid (BALF) were analyzed bi-weekly for a subset of calves (20 calves/treatment) unless otherwise indicated. The subset of calves included 2 calves per pen, resulting in 20 calves per treatment. Per pen, the 2 calves whose arrival body weight was closest to the mean body weight of all calves at arrival, were included in this subset. At the end of the growing period, all calves were slaughtered at week 27, and lungs were scored. The detailed number of calves per treatment and parameter were displayed in Supplementary Table S1.

\section{Clinical Scores}

Clinical scoring was performed weekly for all calves, according to the Wisconsin calf respiratory scoring system [19], in which a score from 0 to 3 was provided for rectal temperature, coughing, nasal discharge and behavior. Clinical score was calculated as the sum of these 4 scores.

Blood Sampling and Hematological Analysis

Blood samples were collected in all calves by venipuncture in the jugular vein at arrival before the first MR feeding (baseline, week 0), and then were collected repeatedly in the subset of calves at experimental weeks 2, 4 and 6. Blood samples were handled under pyrogen (i.e., endotoxin) free conditions. Blood was collected in $\mathrm{K}_{2}$-EDTA tubes and kept on ice for collection of plasma or kept at room temperature for analysis of leukocyte numbers the same day by fluorescence flow cytometry using a Sysmex 1800iV (Sysmex Europe 
$\mathrm{GmbH}$, Norderstedt, Germany), respectively. Plasma was collected after centrifugation at $2000 \times g$ and $4{ }^{\circ} \mathrm{C}$ for $20 \mathrm{~min}$ and was stored at $-20^{\circ} \mathrm{C}$ until analysis.

\section{BALF Sampling and Phenotyping}

BALF samples were collected repeatedly for the same subset of calves (20 calves/treatment) at experimental weeks 1, 3, 5 and 7 and obtained by use of a technique adapted from a previous description [20]. Once the sterilized $100 \mathrm{~cm}$ BAL catheter was wedged in the appropriate location of the lungs, a syringe was connected to the catheter and a total of $30 \mathrm{~mL}$ sterile saline $\left(37^{\circ} \mathrm{C}\right)$ solution was infused into the tube and fluid was immediately aspirated from the bronchus. BALF $(18.1 \pm 0.39 \mathrm{~mL}$, means \pm SEM) was obtained from each calf and was stored in a $50 \mathrm{~mL}$ tube on ice until further analysis the same day. After transport and arrival at the lab, BALF suspension was filtered by passing through a $70 \mu \mathrm{m}$ cell strainer (Corning, New York, NY, USA) to remove debris. Then, BALF suspension was centrifuged ( $5 \mathrm{~min}, 400 \times g$ at $4^{\circ} \mathrm{C}$ ) and the remaining cell pellet was re-suspended in $1 \mathrm{~mL}$ cold fetal bovine serum (FBS). After centrifugation, the supernatant was aliquoted into $1.5 \mathrm{~mL}$ tubes and stored at $-80{ }^{\circ} \mathrm{C}$ for further analysis. The number of the remaining cell pellet was determined by automatically counting in Cellometer Bright Field cell counter (Nexcelom Bioscience, Lawrence, MA, USA). After counting, $0.5 \times 10^{6}$ cells of BALF suspension were used to make cytospins and phenotyping was determined by Diff-Quick (Medion Diagnostics, Medion Diagnostics International Inc., Miami, FL, USA) staining on cytospin preparations and a minimum of 400 cells were counted.

\section{Measurements of Cytokines/Chemokines and M. haemolytica-LPS lgG}

BALF and blood were collected and stored as described above. Concentrations of IL-8 (Mabtech, Nacka Strand, Sweden), IL-6 (Invitrogen, ThermoFisher Scientific, Waltham, MA, USA), IL-1 $\beta$ (Invitrogen) and TNF- $\alpha$ (R\&D Systems, Minneapolis, MN, USA) in BALF and blood were determined by using ELISA kits according to manufacturer's instructions. M. haemolytica-LPS $\operatorname{lgG}$ levels were measured to determine the M. haemolytica positivity in BALF according to manufacturer's instructions (BIO/K-139, Bio-X Diagnostics, Rochefort, Belgium).

\section{Lung Scores}

Lungs of all remaining calves were scored at slaughter according to a scoring system adapted from Leruste et al. [21]. Briefly, each examined lung was classified according to a 4-point scale for pneumonia from healthy lung (score 0 ) to severe lesions (score 3). Score 0 was given for healthy lungs (pale orange color with no sign of pneumonia), score 1 for minimal or mild lesions (one spot of grey-red discoloration), score 2 for moderate lesions (one large or several small spots of grey-red discoloration with a total surface of less than 1 lobe), and score 3 for severe lesions (grey-red discoloration area of at least one full lobe and/or presence of abscesses). The results are shown as a percentage of total calves with different severity of lung lesions, including no/mild and moderate/severe lesions.

\subsection{In Vitro Experiments}

\subsubsection{M. haemolytica Growth, Quantification and Preparation}

M. haemolytica (isolated from a pneumonic bovine lung) was kindly provided by Prof. Jos van Putten (Utrecht University, Utrecht, The Netherlands). M. haemolytica was incubated overnight at $37^{\circ} \mathrm{C}$ in $5 \%$ sheep blood agar (bioTRADING, Mijdrecht, The Netherlands).

Subsequently, M. haemolytica $\left(1 \times 10^{5} \mathrm{CFU} / \mathrm{mL}\right)$ was incubated in 96-well plates with or without FOS $(0.125 \%, 0.25 \%, 0.5 \%, 1 \%$, or $2 \%$; same FOS as in vivo experiment) for $24 \mathrm{~h}$. After incubation, M. haemolytica growth was determined by measuring the turbidity of supernatants at OD600 nm using a microplate reader (Promega Corp., Madison, WI, USA). Then, the supernatants were diluted 50,000-fold and sub-cultured onto 5\% sheep blood agar plates overnight at $37^{\circ} \mathrm{C}$. M. haemolytica numbers were determined by counting CFUs of each plate. 
M. haemolytica $\left(1 \times 10^{5} \mathrm{CFU} / \mathrm{mL}\right)$ were cultured in RPMI-1640 medium containing $10 \%$ FBS (Sigma-Aldrich, Zwijndrecht, The Netherlands) for $24 \mathrm{~h}$ on 6-well plates. Thereafter, the M. haemolytica-cultured supernatants (MHS) were collected and filtered with a $0.25 \mu \mathrm{m}$ filter (GE Healthcare, Chicago, IL, USA).

\subsubsection{Cell Cultures and Treatments}

Isolation and culture of PBECs were conducted as previously described [6]. Briefly, PBECs were isolated from bovine bronchial epithelium obtained from the lungs of freshly slaughtered calves aged 6-8 months, provided by Ekro bv (Apeldoorn, The Netherlands). After digesting of the bronchial epithelium, PBECs were collected and grown in $5 \% \mathrm{CO}_{2}$ at $37^{\circ} \mathrm{C}$ and attached to collagen-coated plates in serum-free RPMI-1640 medium for 2-3 days until reaching near-confluence, and then replaced with RPMI-1640 medium containing $10 \%$ FBS, $1 \%$ L-glutamine, 1\% MEM NEAA, and 1\% penicillin-streptomycin (SigmaAldrich). After that, these PBECs $\left(1 \times 10^{6}\right.$ cells $\left./ \mathrm{mL}\right)$ were first pretreated with different concentrations of FOS $(0.125 \%, 0.25 \%$, or $0.5 \%)$ for $24 \mathrm{~h}$ and then were stimulated with LPS $(10 \mu \mathrm{g} / \mathrm{mL}$; isolated from E. coli O111:B4, Sigma-Aldrich), flagellin $(10 \mathrm{ng} / \mathrm{mL}$; isolated from $P$. aeruginosa, InvivoGen, San Diego, CA, USA), M. haemolytica $\left(1 \times 10^{5} \mathrm{CFU} / \mathrm{mL}\right)$ or MHS for $24 \mathrm{~h}$. After stimulation, supernatants were collected and stored at $-20{ }^{\circ} \mathrm{C}$ until analysis.

Human Type II alveolar epithelial cells (A549; ATCC, Manassas, VA, USA) were grown in Ham's F-12K Medium (Gibco, Thermo Fisher Scientific, Waltham, MA, USA) supplemented with 10\% FBS and 1\% penicillin-streptomycin (Sigma-Aldrich) in 5\% $\mathrm{CO}_{2}$ at $37^{\circ} \mathrm{C}$. After reaching near-confluence, A549 cells $\left(0.5 \times 10^{5}\right.$ cells $\left./ \mathrm{mL}\right)$ were pretreated with $0.5 \%$ FOS for $24 \mathrm{~h}$ prior to $24 \mathrm{~h} \mathrm{LPS}(10 \mu \mathrm{g} / \mathrm{mL}$; isolated from E. coli O111:B4, SigmaAldrich) or flagellin (10 ng/mL; isolated from P. aeruginosa, InvivoGen) stimulation. After stimulation, supernatants were collected and stored at $-20^{\circ} \mathrm{C}$ until analysis.

\subsubsection{Transepithelial Electrical Resistance (TEER) Measurement and Paracellular Tracer Flux Assay}

PBECs $\left(1 \times 10^{6}\right.$ cells $\left./ \mathrm{mL}, 300 \mu \mathrm{L}\right)$ were added to the apical compartment of the permeable $0.3 \mathrm{~cm}^{2}$ high pore density polyethylene membrane transwell inserts (Corning) placed in a 24-well plate and $700 \mu \mathrm{L}$ cell culture medium was added to the basolateral compartment. After that, PBECs were incubated at $37{ }^{\circ} \mathrm{C}$ in $5 \% \mathrm{CO}_{2}$. TEER of PBECs was measured by a Millicell-ERS Volt-Ohm meter (Millipore, Merck, Darmstadt, Germany) every 2 days. The culture medium from the basolateral and apical compartment was refreshed after TEER measurement and experiments started at day 11 when sustained TEER values around $600 \Omega \cdot \mathrm{cm}^{2}$ were reached as described before [6].

PBECs were incubated with $M$. haemolytica $\left(1 \times 10^{5} \mathrm{CFU} / \mathrm{mL}\right)$ from the apical side with or without $24 \mathrm{~h}$ pretreatment with FOS at both apical and basolateral compartments. TEER was measured at 0 and $24 \mathrm{~h}$ after $M$. haemolytica exposure. Thereafter, a membraneimpermeable molecule, lucifer yellow (molecular mass of $0.457 \mathrm{kDa}, 20 \mu \mathrm{g} / \mathrm{mL}$; SigmaAldrich), was added to the apical compartment for $4 \mathrm{~h}$, and the paracellular flux was determined by measuring the fluorescence intensity at the basolateral compartment with a fluorometer (Promega Corp.) at excitation/emission wavelengths of 410/520 nm. After measuring, PBECs were harvested for immunofluorescence staining and Western blotting.

\subsubsection{ELISA Measurement and Lactate dehydrogenase (LDH) Assay}

Levels of IL-8 (Mabtech), IL-6 (Invitrogen), IL-1 $\beta$ (Invitrogen) and TNF- $\alpha$ (R\&D Systems) were determined in the supernatants of PBECs after different treatments by using ELISA kits according to manufacturer's instructions. IL-8 (R\&D Systems) and IL6 (BioLegend, San Diego, CA, USA) release in the supernatants of A549 after different treatments were also measured by ELISA. The absorbance was measured at $450 \mathrm{~nm}$ using a microplate reader (Bio-Rad, Hercules, CA, USA). 
LDH was measured in the supernatants of PBECs or A549 cells after different treatments using the CytoTox 96 nonradioactive cytotoxicity assay kit (Promega Corp.) according to manufacturer's instructions [6].

\subsubsection{Western Blotting}

Western blotting of cell lysates in transwells after different treatments and the information of primary/secondary antibodies were described previously [6]. Digital images were acquired with the Molecular Imager (Gel DocTM XR, Bio-Rad) and analyzed with Image lab 5.0 (Bio-Rad).

\subsubsection{Immunofluorescence}

PBECs were grown in transwells as described above and detected for the tight junction protein zonula occludens-1 (ZO-1) and the adherens junction protein, E-cadherin, using immunofluorescence as previously described [6]. ZO-1 and E-cadherin were visualized, and images were taken using the Keyence BZ-9000 (Osaka, Japan). Fluorescence intensity was quantified by Image J (Version 1.8.0, National Institutes of Health, Bethesda, MD, USA) and presented as fluorescence intensity (vs. DAPI).

\subsection{Statistical Analysis}

Experimental in vivo results were expressed as non-transformed means \pm standard error of mean (SEM). Blood leukocyte and cytokine/chemokine concentrations, BALF total cell, macrophage, neutrophil, and lymphocyte numbers and BALF cytokine/chemokine concentrations were analyzed for treatment and/or time effects with SAS 9.4 (SAS Institute Inc., Cary, NC, USA), using the MIXED procedure, including time as a repeated statement with calf as unit. For each parameter, the covariance structure was selected based on the lowest Akaike Information Criterion (AIC) and Bayesian Information Criterion (BIC). All analyses included a random pen effect. For blood leukocyte concentration, the concentration at arrival (before application of the treatments) was included as a co-variable in the model. Studentized residuals of each model were checked visually on the homogeneity of variance and data were transformed if required to obtain homogeneity of variance. To evaluate differences between treatments, the contrast statement was used, and treatment differences were assessed per timepoint separately. Clinical scores were assessed for treatment and time effects using the GLIMMIX procedure with a multinomial distribution, including a random pen effect and potential differences between the treatments, which were evaluated using the contrast statement per time point. The Chi-square test was performed for the proportion of different lung lesions and the positivity of $M$. haemolytica in calves. Differences were considered significant when $p<0.05$ and considered a trend when $p<0.10$.

Data from in vitro experiments were first checked for normality in the use of the ShapiroWilk normality test. After that, the parametric one-way ANOVA or two-way ANOVA with Tukey's post hoc test was performed for the analyses of cytokine/chemokine release, TEER value, lucifer yellow flux, protein and fluorescence expression, and M. haemolytica growth/CFUs and LDH release. All in vitro results were expressed as means \pm SEM and analyzed using the GraphPad Prism version 7.0 software (GraphPad Software Inc., San Diego, CA, USA). Results were considered significant when $p<0.05$.

\section{Results}

\subsection{Effect of FOS on BALF and Blood Cell Compositions and Clinical and Lung Scores in Calves}

Lung infections were displayed in the naturally exposed calves from week 5 (Figure 1A-E and Supplementary Figure S1). A decreased number of macrophages $(p<0.01)$ and increased number of neutrophils $(p<0.01)$ and lymphocytes $(p<0.01)$ in BALF were observed from week 5 in the control calves, compared to week 1 (Figure 1A-C). The potentially increased total cells (mainly pulmonary leukocytes) in BALF $(p=0.09)$ and increased leukocytes in blood $(p<0.01)$ of control calves were observed at week 5 and 
6, compared to week 1 and 0, respectively (Supplementary Figure S1 and Figure 1D). In addition, the clinical scores increased significantly over time with the peak at week 6 $(p<0.001)$, indicating the presence of lung infections (Figure 1E).

A

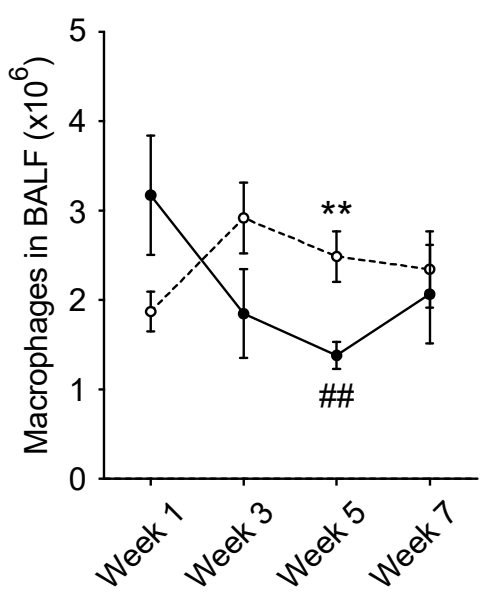

$\mathrm{D}$

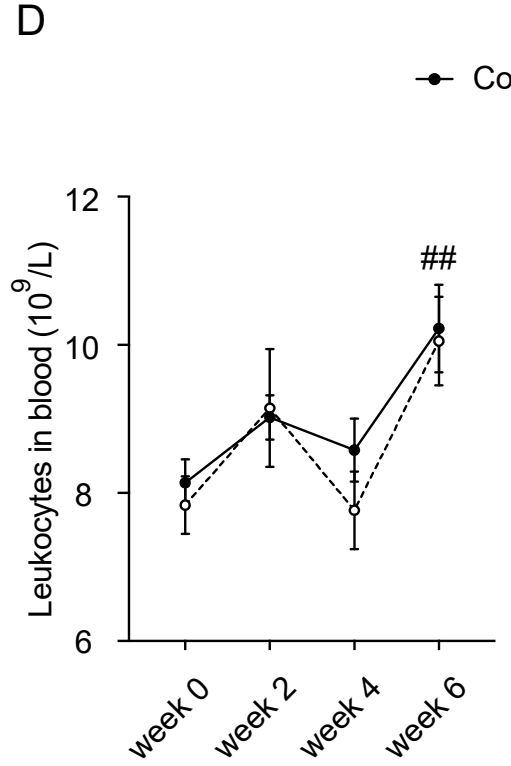

B

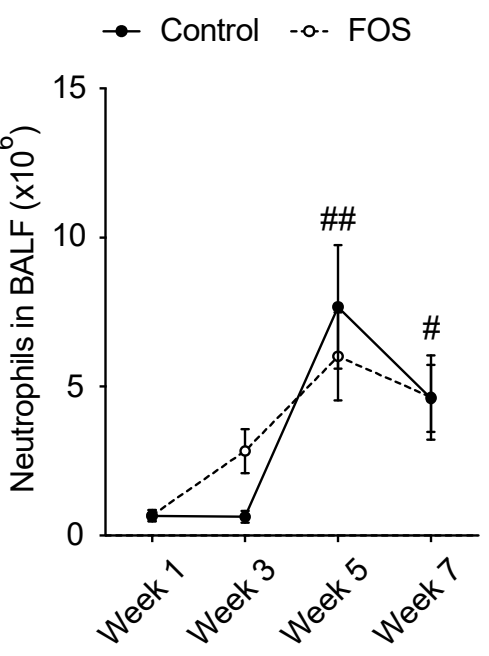

$E$

Control -o. FOS

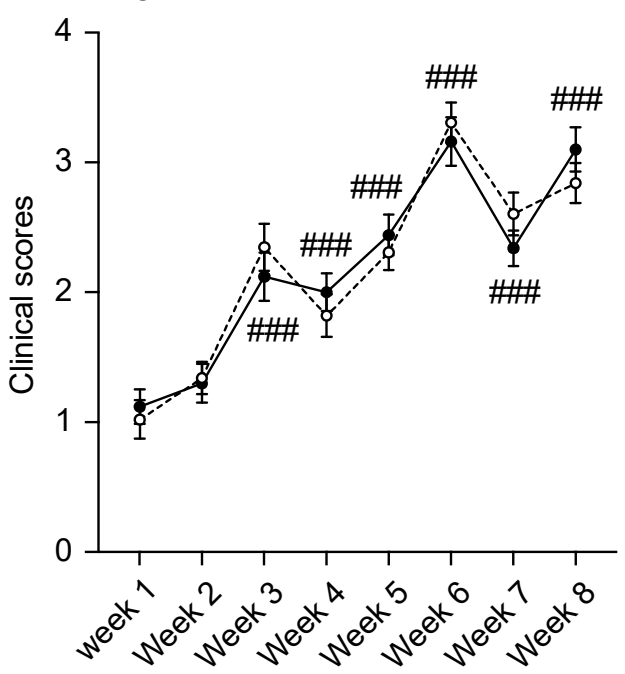

C

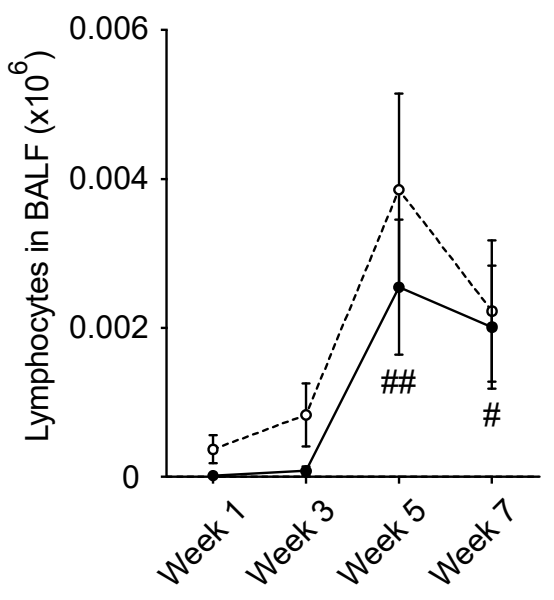

$\mathrm{F}$

Moderate/severe lesions

No/mild lesions

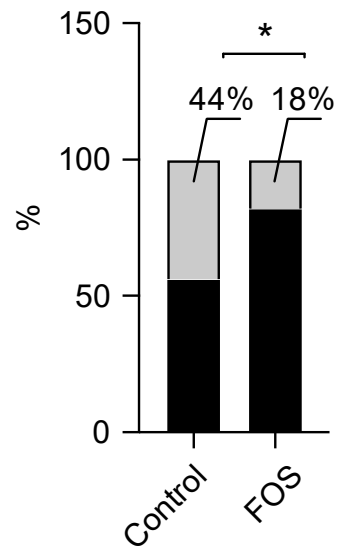

Figure 1. Effect of FOS on BALF and blood cell compositions and clinical and lung scores in calves. Numbers of (A) macrophages, (B) neutrophils, and (C) lymphocytes in BALF and (D) leukocyte concentrations in blood were analyzed for a subset of calves ( $n=40,20$ calves/treatment). (E) Clinical scores and (F) proportion of different lung lesions at slaughter were evaluated for all calves $(n=100,50$ calves/treatment). Significantly different from week 0 or 1 for control: \# $p<0.05$; $\# \# p<0.01$; \#\# $p<0.001$. Significantly different from control at that time: ${ }^{*} p<0.05 ;{ }^{* *} p<0.01$. Data are presented as means \pm SEM unless otherwise indicated. Data are presented as percentage for panel F. BALF, bronchoalveolar lavage fluid; FOS, fructo-oligosaccharides.

FOS-fed calves showed a greater number of BALF macrophages at week $5(p<0.01)$, but no effects on the other parameters of the BALF and blood cell composition were observed (Figure 1A-D and Supplementary Figure S1). The calves fed with dietary FOS showed a lower proportion of moderate/severe lung lesions $(18 \%, p<0.05)$ compared with the control calves (44\%, Figure 1F) at slaughter (week 27). However, FOS had no effects on body weight (data not shown) and clinical scores (Figure 1E) during the experimental period. 
M. haemolytica positivity was investigated in BALF over time. Compared with week 1 $(0 \%)$, the number of $M$. haemolytica positive calves in the control treatment increased to $80 \%$ at week $5(p<0.001)$ and $80 \%$ at week $7(p<0.001)$. A proportion of M. haemolytica-positive calves was unaffected by dietary FOS (Supplementary Table S2).

\subsection{Effect of FOS on Cytokine/Chemokine Concentrations in BALF and Blood of Calves}

The inflammatory response in the lungs was investigated by measuring the cytokines/chemokines in the BALF at week 5. FOS lowered the concentrations of IL-8 $(p<0.05)$, IL-6 $(p<0.05)$, and IL-1 $\beta(p<0.001)$, and tended to also lower the concentration of TNF- $\alpha(p=0.07)$ in BALF at week 5 (Figure 2A-D). The same cytokines/chemokines were measured in blood to investigate the effect of FOS on the systemic inflammation at weeks 4 and 6 . Oral FOS lowered the concentrations of IL-8 $(p<0.001$ and $p<0.01$, respectively), IL-6 ( $p<0.001$ and $p<0.01$, respectively) and IL-1 $\beta(p<0.001$ and $p<0.001$, respectively) in blood at both week 4 and week 6 , while no effects on the TNF- $\alpha$ levels were observed (Figure 2E-H).
A

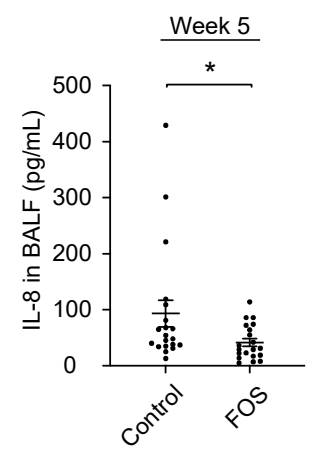

E

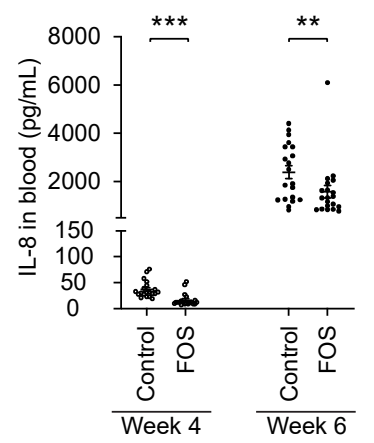

A

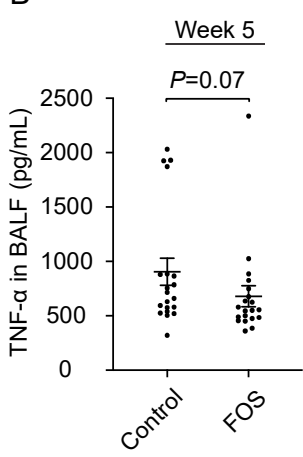

$\mathrm{F}$

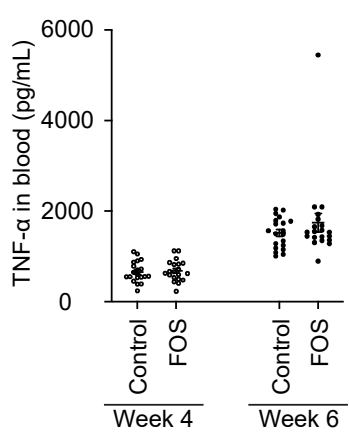

C

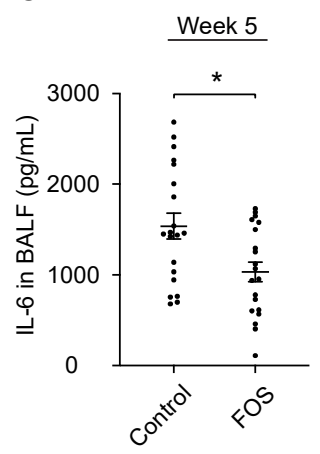

G

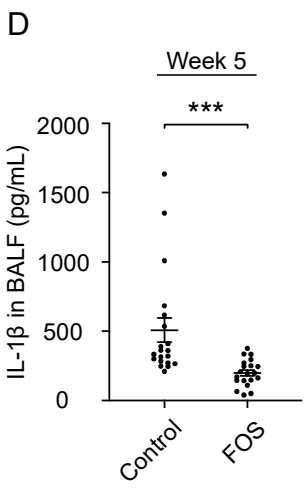

$\mathrm{H}$

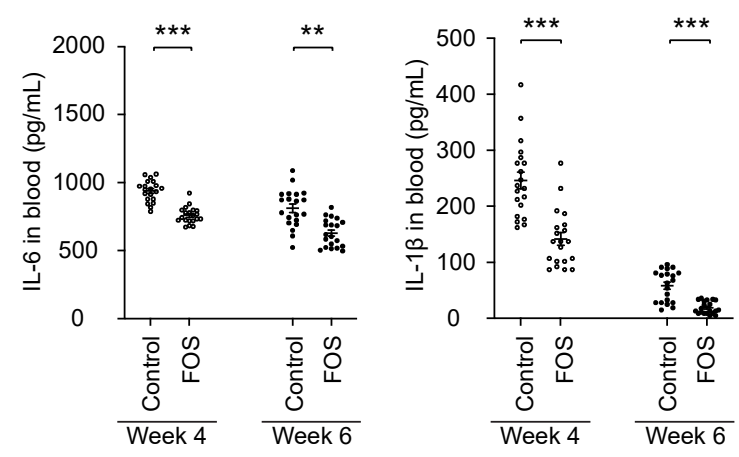

Figure 2. Effect of FOS on cytokine/chemokine concentrations in BALF and blood of calves. (A and E) IL-8, (B and F) TNF- $\alpha,(\mathbf{C}$ and G) IL-6, and (D and H) IL-1 $\beta$ concentrations in BALF and blood were measured for a subset of calves ( $n=40,20$ calves/treatment). Significantly different from control at that time: ${ }^{*} p<0.05 ;{ }^{* *} p<0.01 ;{ }^{* * *} p<0.001$. Data are presented as means \pm SEM. Each dot represents one calf. BALF, bronchoalveolar lavage fluid; FOS, fructo-oligosaccharides; IL, interleukin; TNF, tumor necrosis factor.

\subsection{Effect of FOS on M. haemolytica Growth In Vitro}

Due to the possible presence of FOS in the systemic circulation after oral administration [11-14], different NDOs may exert direct effects on the airway pathogens or epithelial cells. Here, $1 \%$ and $2 \%$ FOS significantly increased the growth $(p<0.01$ and $p<0.01$, respectively) and CFUs ( $p<0.001$ and $p<0.001$, respectively) of $M$. haemolytica in vitro, while FOS $<1 \%$ did not (Figure 3 ). 
A

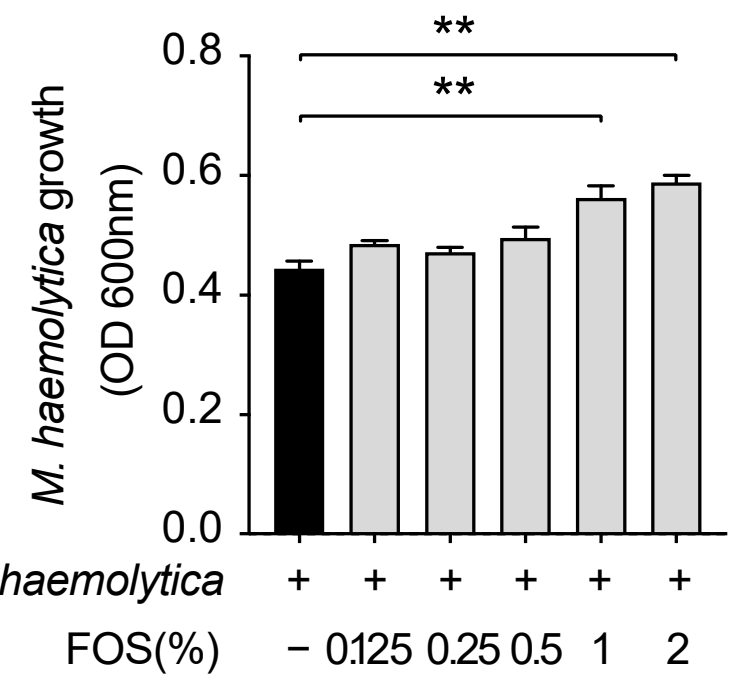

B

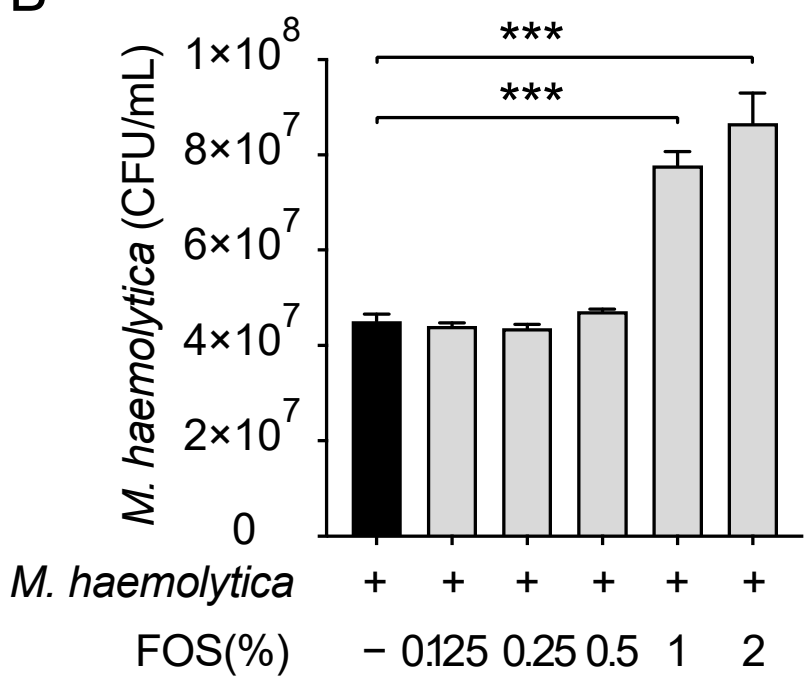

Figure 3. Effect of FOS on M. haemolytica growth in vitro. (A) M. haemolytica growth (OD600 $\mathrm{nm}$ ) in the supernatant and (B) M. haemolytica numbers (CFUs) after subculture of supernatant on the sheep blood agar. Significantly different from M. haemolytica without FOS: ${ }^{* *} p<0.01 ; * * *<0.001$. Data are presented as means $\pm \mathrm{SEM}$. All data shown are representative of five independent experiments ( $n=5$ bacterial generations, one generation per experiment). CFU, colony-forming unit; FOS, fructo-oligosaccharides.

\subsection{Effect of FOS on M. haemolytica-Induced Inflammation in PBECs}

Anti-inflammatory effects of FOS were investigated in an ex vivo infection model based on PBECs of healthy calf lungs [6]. M. haemolytica induced the release of IL-8 $(p<0.001)$, TNF- $\alpha(p<0.001)$ and IL-6 $(p<0.001)$ in PBECs, while the release was significantly inhibited by the pretreatment with $0.5 \%$ FOS $(p<0.001, p<0.001$, and $p<0.001$, respectively) (Figure 4A-C). Moreover, M. haemolytica with or without the pre-administration of FOS did not affect LDH release in PBECs (Figure 4D).

MHS were used as a stimulant for PBECs to investigate whether virulence factors might play a role in the observed anti-inflammatory effect of FOS. MHS successfully induced the release of IL-8 $(p<0.001)$, TNF- $\alpha(p<0.001)$, and IL-6 $(p<0.001)$ in PBECs, while it did not affect the LDH release (Supplementary Figure S2). Pre-incubation with $0.5 \%$ FOS inhibited the MHS-induced IL-8 $(p<0.001)$, TNF- $\alpha(p<0.01)$, and IL-6 $(p<0.01)$ release in PBECs, while no effects in the treatment with FOS alone were observed (Supplementary Figure S2).

\subsection{Effect of FOS on M. haemolytica-Induced Barrier Dysfunction in PBECs}

Another characteristic of M. haemolytica-treated airway epithelial cells was the disruption of the epithelial barrier function [6,22]. M. haemolytica exposure resulted in a significant decrease in TEER ( $p<0.001$; Figure 5A), which facilitated the translocation of lucifer yellow from the apical to the basolateral compartment $(p<0.001$; Figure $5 \mathrm{~B})$. A reduction in the protein level and distribution of the tight junction protein ZO-1 $(p<0.001$ and $p<0.001$, respectively) and the adherens junction protein E-cadherin $(p<0.01$ and $p<0.001$, respectively) was also observed in M. haemolytica-treated PBECs (Figure 5C-E). The pretreatment with $0.5 \%$ FOS prevented the $M$. haemolytica-induced TEER decrease $(p<0.05$; Figure 5A) and increase in lucifer yellow flux $(p<0.01$; Figure 5B), as well as the reduction in ZO-1 $(p<0.01$ and $p<0.001$, respectively) and E-cadherin $(p<0.05$ and $p<0.001$, respectively) expression (Figure 5C-E). 
A

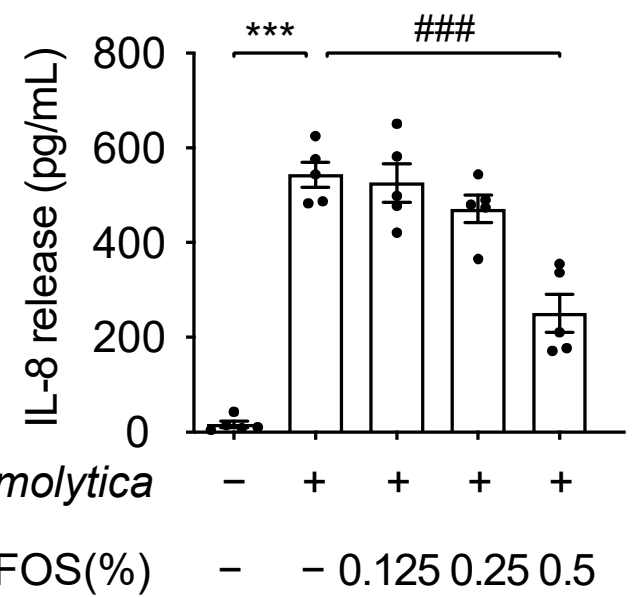

C

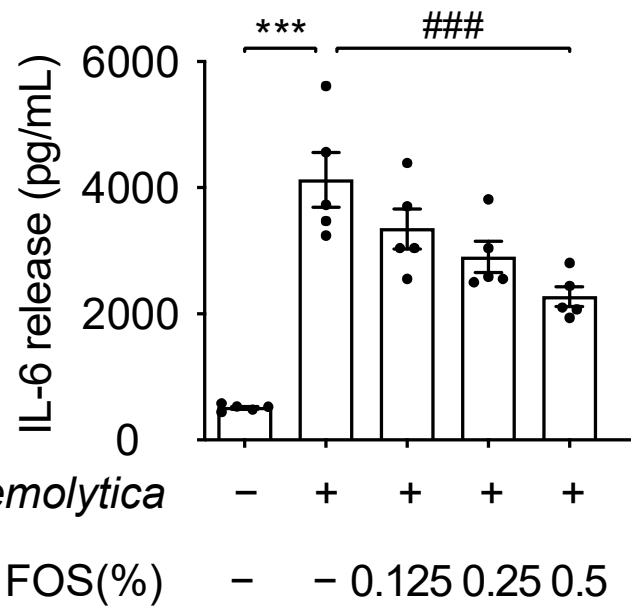

B

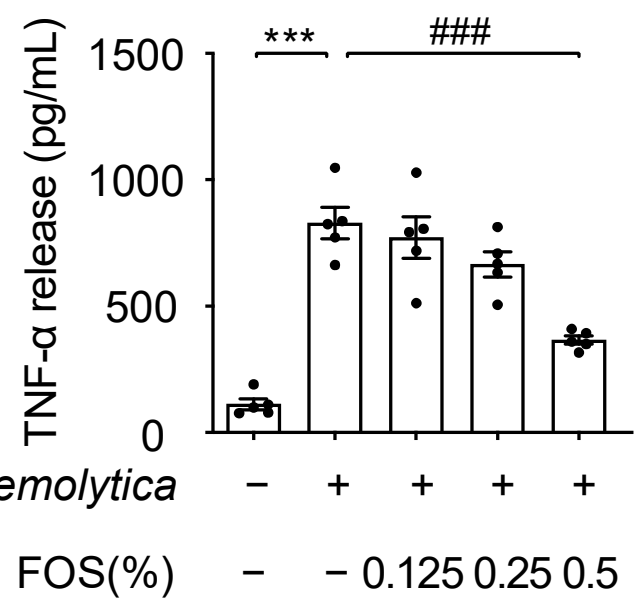

D

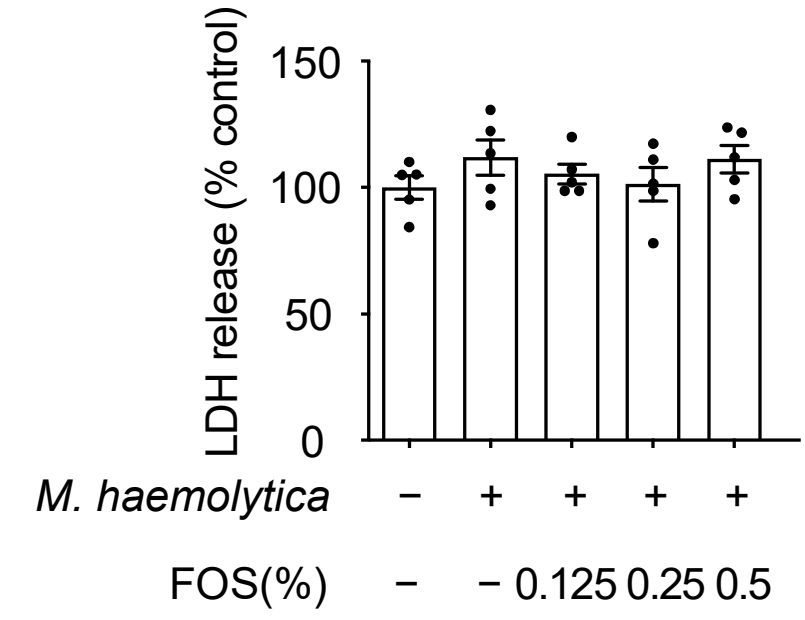

Figure 4. Effect of FOS on M. haemolytica-induced inflammation in PBECs. (A) IL-8, (B) TNF- $\alpha$, (C) IL-6, and (D) LDH release were assessed in the supernatants of PBECs. Significantly different from control: ${ }^{* * *} p<0.001$. Significantly different from M. haemolytica: \#\#\# $p<0.001$. Data are presented as means \pm SEM. All data shown are representative of five independent experiments ( $n=5$ donor calves, one donor calf per experiment). FOS, fructo-oligosaccharides; IL, interleukin; LDH, lactate dehydrogenase; TNF, tumor necrosis factor.

3.6. Effect of FOS on M. haemolytica-Induced Phosphorylation of Mitogen-Activated Protein Kinase (MAPK) and Nuclear Factor (NF)- $\kappa B$ p65 in PBECs

The activation of the MAPK and NF- $\kappa B$ signaling pathways played an important role in the $M$. haemolytica-induced inflammation and barrier dysfunction in PBECs, as observed in our previous study [6]. The pretreatment with $0.5 \%$ FOS showed a decrease in the phosphorylation of p38 MAPK $(p<0.01)$ and NF-кB p65 $(p<0.001)$ in PBECs after $M$. haemolytica exposure (Figure 6). However, FOS did not affect the phosphorylation of extracellular signal-regulated kinase (ERK) $1 / 2$ and c-Jun N-terminal kinase (JNK)1/2 MAPK in the M. haemolytica-treated PBECs (Figure 6). 


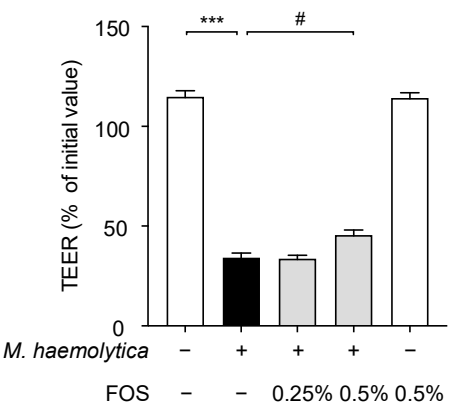

C

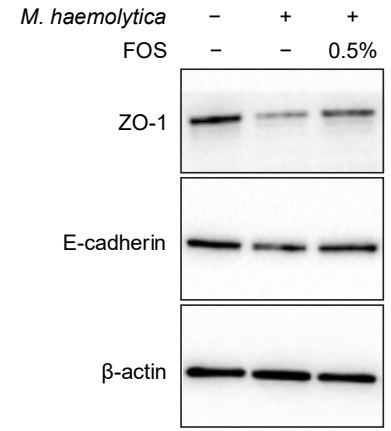

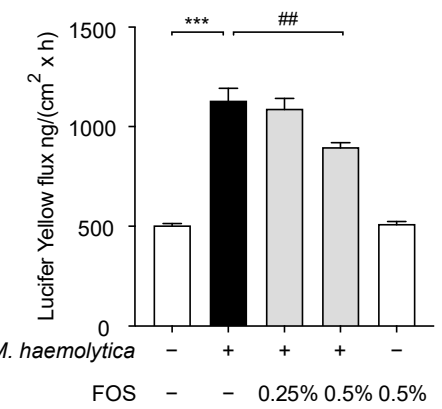

D
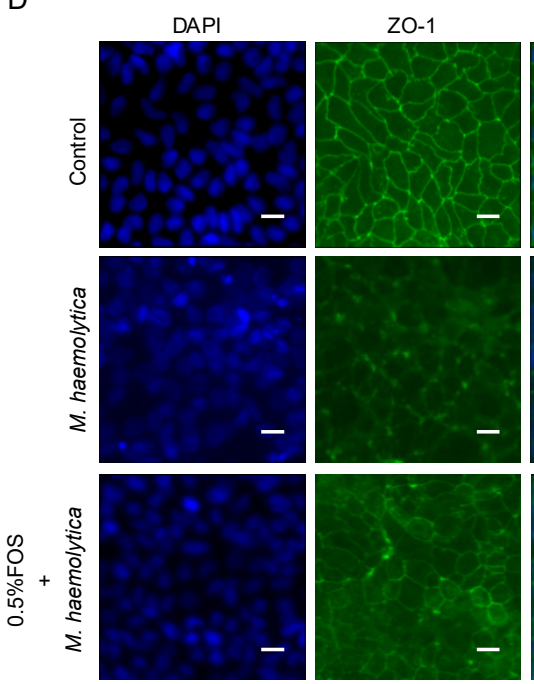

ZO-1

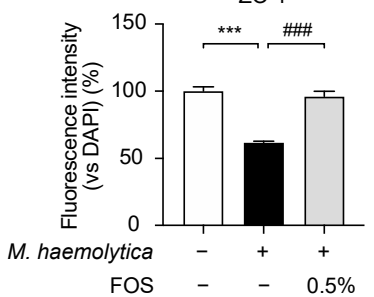

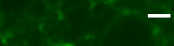
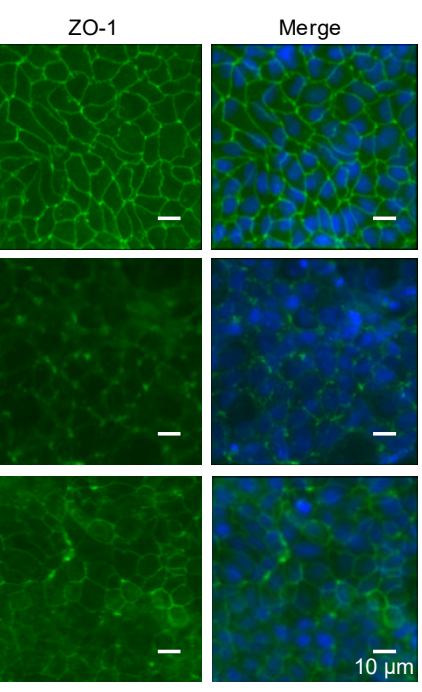

$10 \bar{m}$

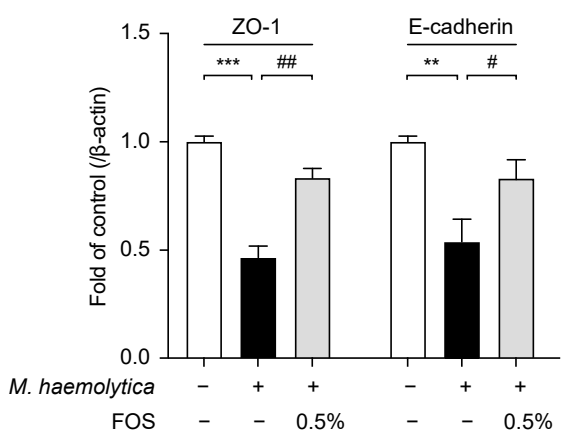

E
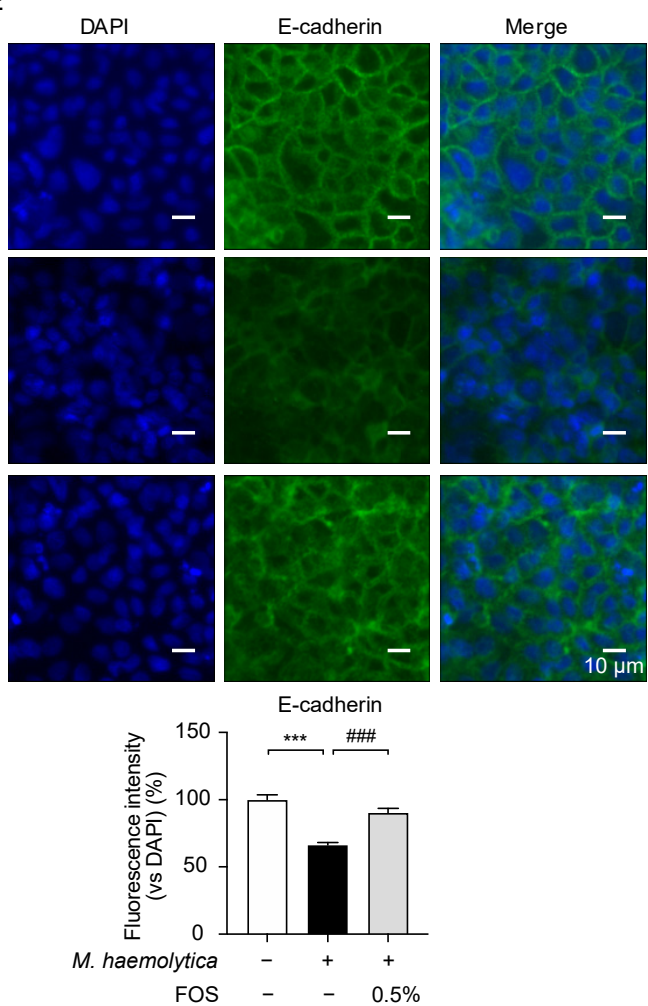

Figure 5. Effect of FOS on M. haemolytica-induced barrier dysfunction in PBECs. (A) TEER was measured and (B) lucifer yellow flux from apical to basolateral compartment was determined in PBECs. (C) The immunoblots were obtained with ZO-1, E-cadherin, and $\beta$-actin (protein loading control). (D,E) Cellular expression of ZO-1 and E-cadherin in PBECs was assessed by immunofluorescent staining and quantified as a percentage of fluorescence intensity. Significantly different from control: ${ }^{* *} p<0.01 ;{ }^{* * *} p<0.001$. Significantly different from M. haemolytica: \# $p<0.05$; \#\# $p<0.01$; \#\#\# $p<0.001$. Data are presented as means \pm SEM. All data shown are representative of at least five independent experiments $(n=5-6$ donor calves, one donor calf per experiment). DAPI, 4', 6-diamidino-2-phenylindole; FOS, fructo-oligosaccharides; TEER, transepithelial electrical resistance; ZO-1, zonula occludens-1. 


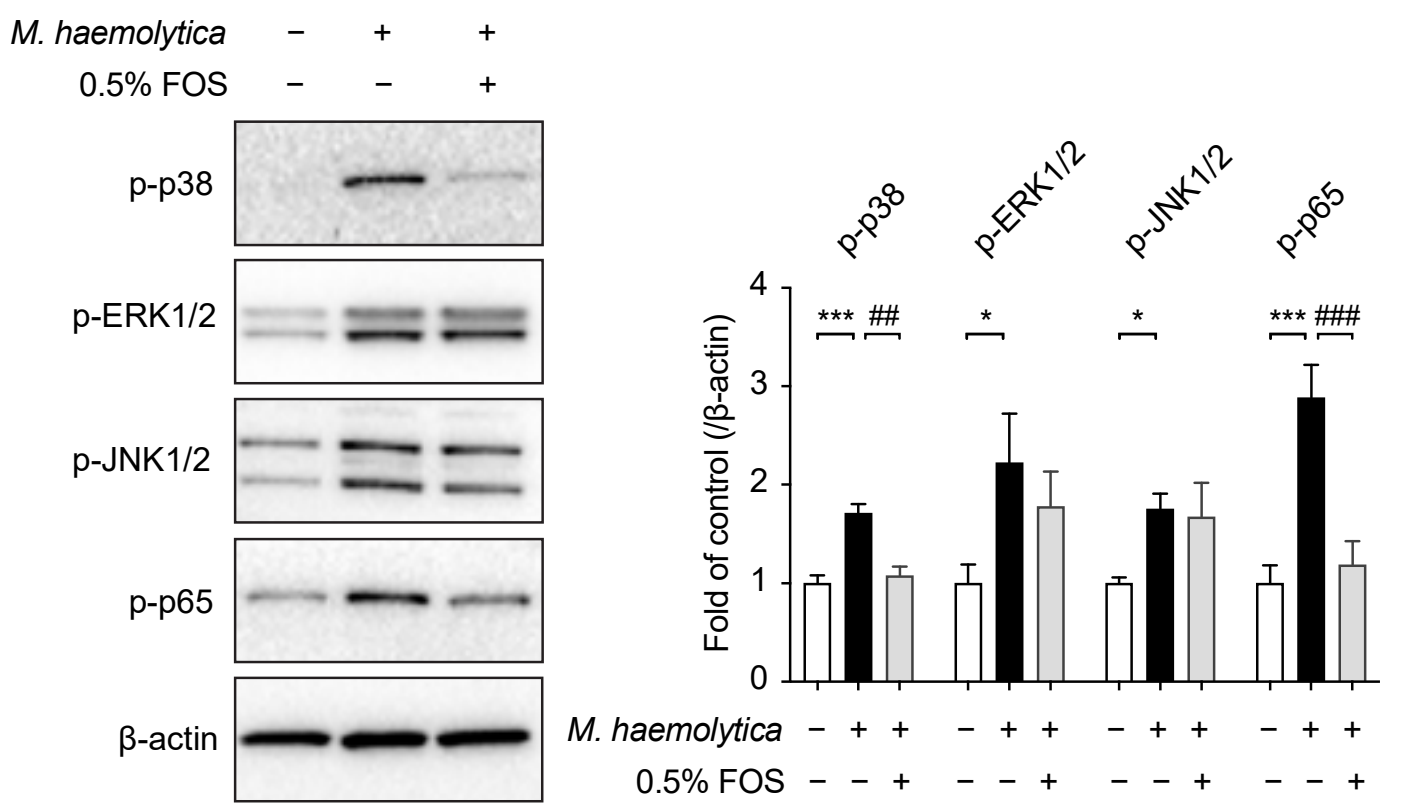

Figure 6. Effect of FOS on M. haemolytica-induced phosphorylation of MAPK and NF- $\mathrm{kB}$ p65 in PBECs. Phosphorylation of p38, ERK1/2, JNK1/2 MAPK and NF- KB p65 were determined by immunoblot and results were shown as a fold of control. Significantly different from control: ${ }^{*} p<0.05$; ${ }^{* *} p<0.001$. Significantly different from M. haemolytica: \#\# $p<0.01$; \#\#\# $p<0.001$. Data are presented as means \pm SEM. All data shown are representative of five independent experiments ( $n=$ five donor calves, one donor calf per experiment). ERK, extracellular signal-regulated kinase; FOS, fructo-oligosaccharides; JNK, c-Jun N-terminal kinase; MAPK, mitogen-activated protein kinase; NF- $\mathrm{kB}$, nuclear factor- $\mathrm{kB}$.

\subsection{The Anti-Inflammatory Effect of FOS Might Be Related to the Interference with TLR5}

Recent studies suggested that NDOs could exert anti-inflammatory effects via TLRs (e.g., TLR4 and TLR5) in host cells [17,23]. FOS suppressed the flagellin (TLR5 ligand)but not the LPS (TLR4 ligand)-induced release of IL-8 $(p<0.05)$, TNF- $\alpha(p<0.01)$, and IL-6 $(p<0.01)$ (Figure 7A-C) in PBECs, while it did not affect the LDH release (Figure 7D). In a human alveolar basal epithelial cell line (A549), FOS inhibited the flagellin-induced release of IL-8 $(p<0.001)$ and TNF- $\alpha(p<0.05)$, but not IL-6 (Supplementary Figure S3D-F). FOS did not affect the LPS-induced cytokine/chemokine release and corresponding LDH release in A549 cells (Supplementary Figure S3A-C, G). 
A

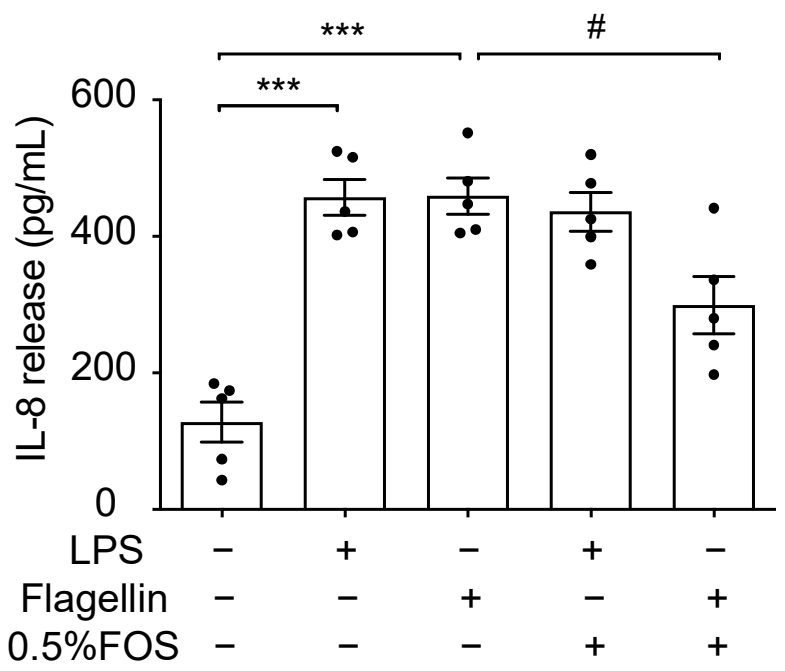

C

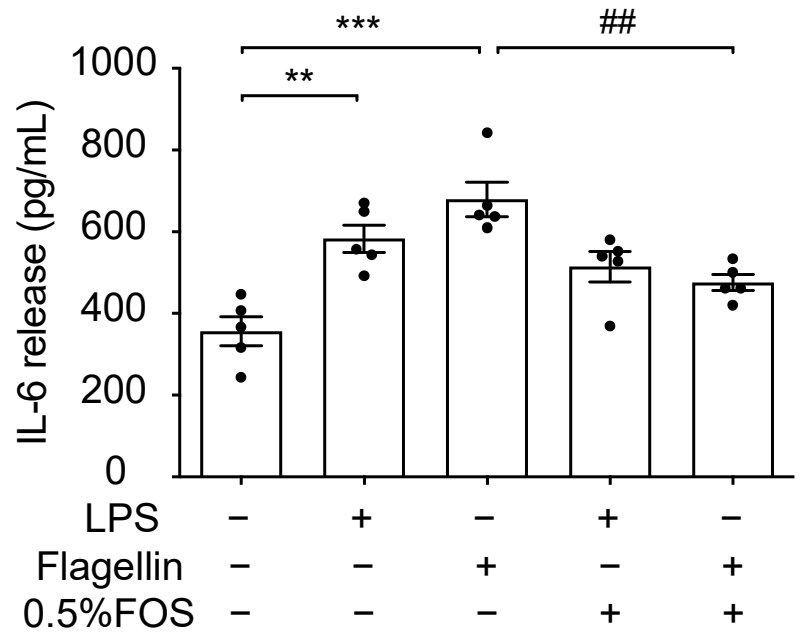

B

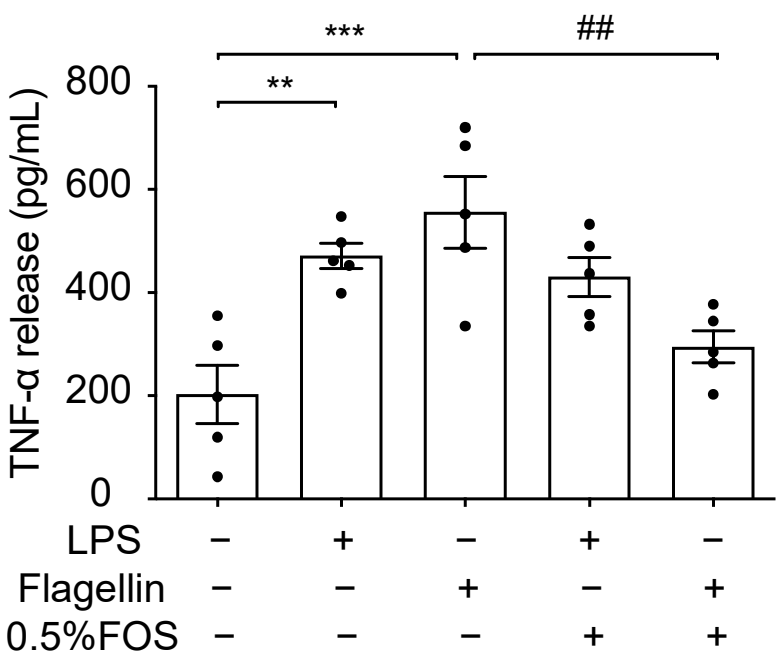

D

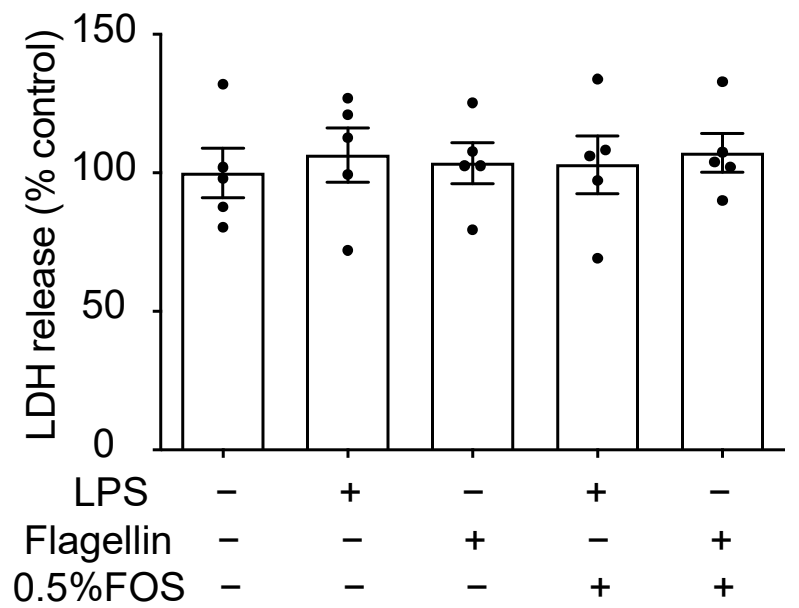

Figure 7. Anti-inflammatory effects of FOS in LPS- or flagellin-treated PBECs. (A) IL-8, (B) TNF- $\alpha$, (C) IL-6, and (D) LDH release were determined in the supernatants of LPS- or flagellin-treated PBECs. Significantly different from control: ${ }^{* *} p<0.01 ;{ }^{* * *} p<0.001$. Significantly different from flagellin: $\# p<0.05 ; \# \#<0.01$. Data are presented as means \pm SEM. All data shown are representative of five independent experiments ( $n=5$ donor calves, one donor calf per experiment). FOS, fructo-oligosaccharides; IL, interleukin; LDH, lactate dehydrogenase; LPS, lipopolysaccharides; TNF, tumor necrosis factor.

\section{Discussion}

This study investigated whether FOS could reduce lung infection and subsequent inflammation. Here, calves naturally exposed to environmental pathogens and M. haemolytica-stimulated PBECs were used to investigate the anti-inflammatory properties of FOS. Different studies demonstrated that NDOs (e.g., FOS, GOS) had beneficial effects on organs besides the intestine, including the airways $[7,24]$, and were therefore a suitable candidate to investigate early dietary intervention to reduce lung infections.

The calf is considered to be a suitable animal model for studying lung infections: the prevalence of pneumonia is extremely high, due to airborne and close contact transmission [2]. However, during natural exposure (in the current study) or in inoculated lung infection models, clinically healthy or asymptomatic individuals were always present $[25,26]$. In order to prevent a high mortality, antibiotic strategies were applied for all calves in the present study, which could postpone the occurrence of lung infections and reduce the 
severity of lung infections. This could be the reason why the effect of oral FOS on BALF cell composition and clinical scores might be underestimated.

Eighty percent of the control calves at week 5 were positive for $M$. haemolytica (in BALF). We observed that FOS could inhibit the M. haemolytica-induced inflammation in PBECs (ex vivo), and there were indications that FOS could be absorbed into the systemic circulation after oral administration [11-14]. Therefore, it might be possible that FOS specifically inhibited the $M$. haemolytica-induced inflammation in calves. The insensitivity of clinical scores to diagnose (subclinical) lung infections may also lead to contrasting results as compared to the measurements of cell composition and cytokine/chemokine levels in the BALF/blood [27]. Although the clinical scores did not differ, the lung lesions at slaughter appeared less severe for FOS-supplemented calves. In the future, additional experiments with different dosages, different treatment periods, and different routes of application are needed to optimize FOS supplementation in clinical practice.

FOS intervention was applied during the first 8 weeks after arriving at the facility, since calves were clearly at the highest risk of naturally occurring lung infections within the first 8 weeks after transport/arrival [28] and, during these first two months after transport/arrival, the calves also received frequent antibacterial drugs to treat such (lung) infections. The calves in the present study originated from a diverse background (i.e., different farms), were transported under stressful conditions, had to deal with dietary changes, and were therefore at a particularly high risk of respiratory diseases. Although the calves did not receive FOS intervention after experimental week 8, the FOS-fed calves still showed a reduced severity of lung lesions after 27 weeks, which might be due to the reduction in inflammatory infiltration caused by the decreased cytokine/chemokine levels. In addition, elevated macrophage numbers in the BALF induced by oral FOS might contribute to reducing lung lesions and inflammation [2]. Most reported studies focused on the well-known intestinal protection and prebiotic effects of oligosaccharides, while there were few studies related to respiratory diseases. For instance, a dietary intervention with $1 \%$ GOS suppressed the increased BALF leukocyte numbers and CCL5 and IL-13 levels in a murine house dust mite-induced asthma model [29]. Additionally, a mixture of GOS/lcFOS/pectin supplementation decreased the BALF neutrophil numbers in mice with LPS-induced lung emphysema [7]. Moreover, dietary pAOS recruited polynuclear leukocytes and macrophages, and decreased TNF- $\alpha$ release in the lung, leading to an increased bacterial clearance after P. aeruginosa infection in mice [8]. In the present study, dietary FOS increased the total cells (mainly macrophages) and macrophages in the BALF at weeks 3 and 5, respectively. In particular, the increased macrophages might be helpful in contributing to bacterial clearance after lung infections in calves. It was reported that alveolar macrophages, as resident immune cells in the epithelial mucosa of the lower respiratory tract, played an important role in respiratory defense, including the rapid response to phagocytose pathogens and cell debris [2].

The promising anti-inflammatory effects of FOS both systemically and locally, as observed by the lower IL- 8 , IL- 6 , and IL- $1 \beta$ levels in the BALF and blood, might be (partly) related to the crosstalk between the gut (rumen) microbiota and the lungs, i.e., the gut-lung axis [30]. In a randomized trial with children, consuming long-chain FOS (lcFOS) resulted in a higher relative abundance of Bifidobacteria and Lactobacillus in feces and fewer incidence of febrile episodes and sinusitis [31]. An in vitro study found that FOS fermentation resulted in greater acetate and butyrate concentrations and enhanced growth of Lactobacilli, Streptococci and lactic acid utilizing bacteria in veal calf ileal contents [32]. In the present study, more dietary fibers (than FOS) were present in the MR (e.g., pea fiber) and solid feed (e.g., wheat straw and barley) of all calves. Most likely, the amount of short-chain fatty acids (SCFAs) produced from those additional fiber sources was much higher than compared to the SCFA related the FOS supplementation.

In addition to the possible indirect mechanisms via the gut-lung axis and inhibited systemic inflammation, there might be a possibility that FOS directly interacts with airway epithelial cells and respiratory pathogens after oral administration. There is some evidence 
that FOS have the ability to cross the intestinal epithelial barrier and might reach the lungs (bronchus) through blood circulation [11-14], resulting in the direct inhibition of inflammation and protection of the epithelial barrier function in the airways. In an experiment in rats, different HMOs (2'-fucosyllactose, 2'-FL; 6'-sialyllactose, 6'-SL; and lacto-N-neotetraose, $\mathrm{LNnT}$ ) administered orally were detected in blood and urine [11]. Our previous study with piglets reported that, after the oral ingestion of GOS ( $0.8 \%$ GOS, DP 2-6, once per day), around $0.1 \%$ GOS was observed in blood serum and approximately $0.85 \mathrm{~g}$ GOS $/ \mathrm{g}$ creatinine was found in urine [13]. Moreover, Eiwegger et al. showed in vitro evidence for the transport of prebiotic oligosaccharides, similar to FOS, across the intestinal epithelial layer, whereas the lower DPs of the oligosaccharides exerted a higher transmission in crossing the intestinal epithelial layer [14]. In the present study, FOS (DP 2-8) supplemented to MR might cross the intestinal epithelial layer and exert direct (systemic) effects on other organs, such as the lungs. However, we did not investigate the in vivo fate of FOS in the calves used in this study; therefore, the exact concentration of FOS in local lung tissue and systemic circulation of calves/ruminants is not available and warrants further research.

Previously studies often focused on the beneficial effects of FOS on intestinal cells, while here we investigated the direct effects of FOS on the airway epithelial cells. $0.5 \%$ FOS inhibited the release of cytokines/chemokines (IL-8, IL-6, and TNF- $\alpha$ ) in M. haemolyticastimulated PBECs, indeed suggesting the possible direct anti-inflammatory capacity of FOS in the airways. Concentrations higher than $0.5 \%$ FOS were not investigated in this in vitro study as $>0.5 \%$ FOS promoted the growth of M. haemolytica. It can be suggested that FOS might be used as a beneficial carbon source for $M$. haemolytica growth and survival in vitro. Additionally, we can exclude the possibility that the anti-inflammatory effects of FOS observed in vitro are related to $M$. haemolytica growth inhibition or bacterial killing. The accumulation of inflammatory cytokines (e.g., IL- 6 and TNF- $\alpha$ ) caused by infections in the airways is one of the most significant causes for the sustained impairment of the epithelial barrier function [2,33-35]. We showed that FOS have the ability to inhibit the levels of these cytokines in vitro and in vivo, thereby protecting the integrity of the epithelial barrier, as observed by a higher TEER value and the expression of tight/adherens junction proteins, and the lower lucifer yellow flux in PBECs. In addition, FOS may have direct protective effects on the epithelial barrier via the modulation of host cell signaling in the epithelium [36]. Our previous study indicated that $2 \%$ FOS could significantly modulate the deoxynivalenol-induced epithelial barrier disruption in Caco-2 cells [37].

In studies describing the anti-inflammatory properties of NDOs, the potential role of TLR modulation, such as TLR4 and 5 regulations, in cytokine production has been demonstrated $[15,23]$. It has also been reported that specific NDOs, such as FOS and GOS, may affect the inflammatory signal transduction pathways mediated by TLRs/NF$\kappa B$ and secondarily by MAPK [16]. In the present study, FOS were able to inhibit the M. haemolytica-induced release of cytokines/chemokines (IL-8, IL-6, and TNF- $\alpha$ ) and the phosphorylation of NF- $\mathrm{kB}$ p65 and p38 MAPK in PBECs. Our studies with MHS-stimulated PBECs showed that the anti-inflammatory effects of FOS were not related to the direct interaction with $M$. haemolytica, but other factors, such as virulence factors and other mediators may play a role in this process. We observed that FOS inhibited flagellin- but not LPS-induced inflammatory responses, which might be related to the interference with the TLR5 signaling in PBECs and A549 cells. Specific HMOs (2'-FL, 6'-SL, LNnT, and 3fucosyllactose) also suppressed the flagellin-induced TLR5 activation in HEK-Blue hTLR5 cells but did not affect the LPS-induced TLR4 activation in HEK-Blue hTLR4 cells [23]. There is no evidence in the literature that $M$. haemolytica produces flagellin; therefore, FOS might inhibit the inflammatory response caused by other virulence factors (e.g., LPS) by interfering with TLR5 signaling. It could be possible that higher FOS concentrations are needed to modulate the LPS-induced inflammatory response in PBECs. A recent study in TLR5-deficient mice showed that a decreased cytokine expression in the lungs was observed after LPS exposure in the lungs, which might be due to the participation of TLR5 in TLR4-dependent signaling [38]. 


\section{Conclusions}

Overall, to our knowledge, this is the first study that used FOS to relieve lung infections in calves. Interestingly, FOS had the capability to reduce lung inflammation in infected calves, systemically and locally, and prevent $M$. haemolytica-induced epithelial barrier dysfunction and inflammatory responses ex vivo, which might be due to the interference with TLR5 signaling. The suppression of infection-induced inflammation by FOS may contribute to alleviating respiratory diseases in animals and humans.

Supplementary Materials: The following are available online at https://www.mdpi.com/article/ 10.3390/nu13103514/s1, Figure S1: FOS have no effects on total cell numbers in BALF of calves, Figure S2: Effect of FOS on MHS-induced inflammation in PBECs, Figure S3: Anti-inflammatory effects of FOS in LPS- or flagellin-treated human airway epithelial cells, Table S1: The number of calves per treatment and parameter, Table S2: The number of calves positive for M. haemolytica in BALF over time.

Author Contributions: Conceptualization, Y.C., S.B., G.F., M.S.G., and W.J.J.G.; methodology, Y.C., S.B., and M.S.G.; validation, Y.C. and M.S.G.; formal analysis, Y.C. and M.S.G.; writing—original draft preparation, Y.C.; writing—review and editing, S.B., G.F., M.S.G. and W.J.J.G.; visualization, Y.C.; supervision, S.B. and G.F.; project administration, G.F. and W.J.J.G.; funding acquisition, G.F. and W.J.J.G. All authors have read and agreed to the published version of the manuscript.

Funding: This research was performed in the public-private partnership 'CarboKinetics' coordinated by the Carbohydrate Competence Center (CCC, www.cccresearch.nl, accessed on 12 August 2021). CarboKinetics is financed by participating industrial partners: Agrifirm Innovation Center B.V., Cooperatie AVEBE U.A., DSM Food Specialties B.V., FrieslandCampina Nederland B.V., Nutrition Sciences N.V., VanDrie Holding N.V. and Sensus B.V., and allowances of The Netherlands Organisation for Scientific Research (NWO; No. ALWCC.2015.4). Research grant funding (No. 201608320245) was received from the China Scholarship Council for Y. Cai.

Institutional Review Board Statement: The animal experiment was conducted under the Dutch Law on Animal Experiments in accordance with EU Directive 2010/63 at the research facilities of the VanDrie Group (Scherpenzeel, The Netherlands) and was approved by the Animal Care and Use Committee of Wageningen University (AVD1040020185828, Wageningen, The Netherlands).

Informed Consent Statement: Not applicable.

Data Availability Statement: The data presented in this study are available on request from the corresponding author.

Acknowledgments: The authors are grateful to Jos van Putten for providing free access to all the facilities of his laboratory and for providing the Mannheimia haemolytica strain.

Conflicts of Interest: The authors declare no conflict of interest.

\section{References}

1. Mizgerd, J.P. Acute Lower Respiratory Tract Infection. N. Engl. J. Med. 2008, 358, 716-727. [CrossRef] [PubMed]

2. Caswell, J.L. Failure of Respiratory Defenses in the Pathogenesis of Bacterial Pneumonia of Cattle. Vet. Pathol. 2013, 51, $393-409$. [CrossRef] [PubMed]

3. Duff, G.C.; Galyean, M.L. Board-invited review: Recent advances in management of highly stressed, newly received feedlot cattle. J. Anim. Sci. 2007, 85, 823-840. [CrossRef]

4. Singh, K.; Ritchey, J.W.; Confer, A.W. Mannheimia haemolytica: Bacterial-host interactions in bovine pneumonia. Vet. Pathol. 2010, 48, 338-348. [CrossRef] [PubMed]

5. Vareille, M.; Kieninger, E.; Edwards, M.R.; Regamey, N. The Airway Epithelium: Soldier in the Fight against Respiratory Viruses. Clin. Microbiol. Rev. 2011, 24, 210-229. [CrossRef] [PubMed]

6. Cai, Y.; Varasteh, S.; van Putten, J.; Folkerts, G.; Braber, S. Mannheimia haemolytica and lipopolysaccharide induce airway epithelial inflammatory responses in an extensively developed ex vivo calf model. Sci. Rep. 2020, 10, 1-14. [CrossRef]

7. Janbazacyabar, H.; Van Bergenhenegouwen, J.; Verheijden, K.A.; Leusink-Muis, T.; Van Helvoort, A.; Garssen, J.; Folkerts, G.; Braber, S. Non-digestible oligosaccharides partially prevent the development of LPS-induced lung emphysema in mice. Pharma Nutr. 2019, 10, 100163. [CrossRef] 
8. Bernard, H.; Desseyn, J.-L.; Bartke, N.; Kleinjans, L.; Stahl, B.; Belzer, C.; Knol, J.; Gottrand, F.; Husson, M.-O. Dietary pectinderived acidic oligosaccharides improve the pulmonary bacterial clearance of pseudomonas aeruginosalung infection in mice by modulating intestinal microbiota and immunity. J. Infect. Dis. 2015, 211, 156-165. [CrossRef]

9. Arslanoglu, S.; Moro, G.E.; Boehm, G. Early supplementation of prebiotic oligosaccharides protects formula-fed infants against infections during the first 6 months of life. J. Nutr. 2007, 137, 2420-2424. [CrossRef]

10. Arslanoglu, S.; Moro, G.E.; Schmitt, J.; Tandoi, L.; Rizzardi, S.; Boehm, G. Early Dietary Intervention with a Mixture of Prebiotic Oligosaccharides Reduces the Incidence of Allergic Manifestations and Infections during the First Two Years of Life. J. Nutr. 2008, 138, 1091-1095. [CrossRef]

11. Vazquez, E.; Santos-Fandila, A.; Buck, R.; Rueda, R.; Ramirez, M. Major human milk oligosaccharides are absorbed into the systemic circulation after oral administration in rats. Br. J. Nutr. 2017, 117, 237-247. [CrossRef]

12. Ruhaak, L.R.; Stroble, C.; Underwood, M.A.; Lebrilla, C.B. Detection of milk oligosaccharides in plasma of infants. Anal. Bioanal. Chem. 2014, 406, 5775-5784. [CrossRef] [PubMed]

13. Difilippo, E.; Bettonvil, M.; Willems, R.; Braber, S.; Fink-Gremmels, J.; Jeurink, P.V.; Schoterman, M.H.C..; Gruppen, H.; Schols, H.A. Oligosaccharides in Urine, Blood, and Feces of Piglets Fed Milk Replacer Containing Galacto-oligosaccharides. J. Agric. Food Chem. 2015, 63, 10862-10872. [CrossRef] [PubMed]

14. Eiwegger, T.; Stahl, B.; Haidl, P.; Schmitt, J.; Boehm, G.; Dehlink, E.; Urbanek, R.; Szépfalusi, Z. Prebiotic oligosaccharides: In vitro evidence for gastrointestinal epithelial transfer and immunomodulatory properties. Pediatr. Allergy Immunol. 2010, 21, 1179-1188. [CrossRef]

15. He, Y.; Lawlor, N.; Newburg, D.S. Human Milk Components Modulate Toll-Like Receptor-Mediated Inflammation. Adv. Nutr. 2016, 7, 102-111. [CrossRef] [PubMed]

16. Ortega, M.D.S.; Ocón, B.; Calvo, I.R.; Anzola, A.; Guadix, E.M.; Zarzuelo, A.; Suárez, M.D.; de Medina, F.S.; Martínez-Augustin, O. Nondigestible oligosaccharides exert nonprebiotic effects on intestinal epithelial cells enhancing the immune response via activation of TLR4-NFkB. Mol. Nutr. Food Res. 2013, 58, 384-393. [CrossRef] [PubMed]

17. Cai, Y.; Folkerts, J.; Folkerts, G.; Maurer, M.; Braber, S. Microbiota-dependent and -independent effects of dietary fibre on human health. Br. J. Pharmacol. 2020, 177, 1363-1381. [CrossRef] [PubMed]

18. Baral, P.; Batra, S.; Zemans, R.L.; Downey, G.P.; Jeyaseelan, S. Divergent functions of toll-like receptors during bacterial lung infections. Am. J. Respir. Crit. Care Med. 2014, 190, 722-732. [CrossRef]

19. McGuirk, S.M.; Peek, S.F. Timely diagnosis of dairy calf respiratory disease using a standardized scoring system. Anim. Health Res. Rev. 2014, 15, 145-147. [CrossRef]

20. Caldow, G. Bronchoalveolar lavage in the investigation of bovine respiratory disease. Practice 2001, 23, 41-43. [CrossRef]

21. Leruste, H.; Brscic, M.; Heutinck, L.; Visser, E.; Wolthuis-Fillerup, M.; Bokkers, E.; Stockhofe-Zurwieden, N.; Cozzi, G.; Gottardo, F.; Lensink, B.; et al. The relationship between clinical signs of respiratory system disorders and lung lesions at slaughter in veal calves. Prev. Vet. Med. 2012, 105, 93-100. [CrossRef]

22. Cozens, D.; Sutherland, E.; Lauder, M.; Taylor, G.; Berry, C.C.; Davies, R.L. Pathogenic Mannheimia haemolytica Invades Differentiated Bovine Airway Epithelial Cells. Infect. Immun. 2019, 87, e00078-19. [CrossRef] [PubMed]

23. Cheng, L.; Kiewiet, M.B.; Groeneveld, A.; Nauta, A.; de Vos, P. Human milk oligosaccharides and its acid hydrolysate LNT2 show immunomodulatory effects via TLRs in a dose and structure-dependent way. J. Funct. Foods 2019, 59, 174-184. [CrossRef]

24. Bruzzese, E.; Volpicelli, M.; Squeglia, V.; Bruzzese, D.; Salvini, F.; Bisceglia, M.; Lionetti, P.; Cinquetti, M.; Iacono, G.; Amarri, S.; et al. A formula containing galacto- and fructo-oligosaccharides prevents intestinal and extra-intestinal infections: An observational study. Clin. Nutr. 2009, 28, 156-161. [CrossRef] [PubMed]

25. Amat, S.; Alexander, T.W.; Holman, D.B.; Schwinghamer, T.; Timsit, E. Intranasal Bacterial Therapeutics Reduce Colonization by the Respiratory Pathogen Mannheimia haemolytica in Dairy Calves. mSystems 2020, 5. [CrossRef] [PubMed]

26. Van Driessche, L.; Valgaeren, B.; Gille, L.; Boyen, F.; Ducatelle, R.; Haesebrouck, F.; Deprez, P.; Pardon, B. A Deep Nasopharyngeal Swab Versus Nonendoscopic Bronchoalveolar Lavage for Isolation of Bacterial Pathogens from Preweaned Calves With Respiratory Disease. J. Vet. Intern. Med. 2017, 31, 946-953. [CrossRef]

27. van Leenen, K.; Van Driessche, L.; De Cremer, L.; Masmeijer, C.; Boyen, F.; Deprez, P.; Pardon, B. Comparison of bronchoalveolar lavage fluid bacteriology and cytology in calves classified based on combined clinical scoring and lung ultrasonography. Prev. Veter-Med. 2020, 176, 104901. [CrossRef]

28. Pardon, B.; De Bleecker, K.; Hostens, M.; Callens, J.; Dewulf, J.; Deprez, P. Longitudinal study on morbidity and mortality in white veal calves in Belgium. BMC Vet. Res. 2012, 8, 26. [CrossRef]

29. Verheijden, K.A.T.; Willemsen, L.E.M.; Braber, S.; Leusink-Muis, T.; Delsing, D.J.M.; Garssen, J.; Kraneveld, A.D.; Folkerts, G. Dietary galacto-oligosaccharides prevent airway eosinophilia and hyperresponsiveness in a murine house dust mite-induced asthma model. Respir. Res. 2015, 16, 1-9. [CrossRef]

30. Budden, K.F.; Gellatly, S.L.; Wood, D.L.A.; Cooper, M.A.; Morrison, M.; Hugenholtz, P.; Hansbro, P.M. Emerging pathogenic links between microbiota and the gut-lung axis. Nat. Rev. Microbiol. 2017, 15, 55-63. [CrossRef]

31. Lohner, S.; Jakobik, V.; Mihályi, K.; Soldi, S.; Vasileiadis, S.; Theis, S.; Sailer, M.; Sieland, C.; Berényi, K.; Boehm, G.; et al. Inulin-Type Fructan Supplementation of 3- to 6-Year-Old Children Is Associated with Higher FecalBifidobacteriumConcentrations and Fewer Febrile Episodes Requiring Medical Attention. J. Nutr. 2018, 148, 1300-1308. [CrossRef] 
32. Philippeau, C.; Respondek, F.; Julliand, V. In vitro effects of fructo-oligosaccharides on bacterial concentration and fermentation profiles in veal calf ileal contents. Anim. Feed. Sci. Technol. 2010, 162, 83-90. [CrossRef]

33. Siegel, S.J.; Weiser, J.N. Mechanisms of Bacterial Colonization of the Respiratory Tract. Annu. Rev. Microbiol. 2015, 69, 425-444. [CrossRef]

34. Coyne, C.B.; VanHook, M.K.; Gambling, T.M.; Carson, J.L.; Boucher, R.C.; Johnson, L.G. Regulation of Airway Tight Junctions by Proinflammatory Cytokines. Mol. Biol. Cell 2002, 13, 3218-3234. [CrossRef]

35. Jevnikar, Z.; Östling, J.; Ax, E.; Calvén, J.; Thörn, K.; Israelsson, E.; Öberg, L.; Singhania, A.; Lau, L.C.; Wilson, S.J.; et al. Epithelial IL-6 trans-signaling defines a new asthma phenotype with increased airway inflammation. J. Allergy Clin. Immunol. 2019, 143, 577-590. [CrossRef]

36. Wu, R.Y.; Abdullah, M.; Määttänen, P.; Pilar, A.V.C.; Scruten, E.; Johnson-Henry, K.C.; Napper, S.; O’Brien, C.; Jones, N.L.; Sherman, P.M. Protein kinase $C \delta$ signaling is required for dietary prebiotic-induced strengthening of intestinal epithelial barrier function. Sci. Rep. 2017, 7, 40820. [CrossRef] [PubMed]

37. Akbari, P.; Fink-Gremmels, J.; Willems, R.H.A.M.; DiFilippo, E.; Schols, H.A.; Schoterman, M.H.C.; Garssen, J.; Braber, S. Characterizing microbiota-independent effects of oligosaccharides on intestinal epithelial cells: Insight into the role of structure and size: Structure-activity relationships of non-digestible oligosaccharides. Eur. J. Nutr. 2017, 56, 1919-1930. [CrossRef] [PubMed]

38. Hussain, S.; Johnson, C.G.; Sciurba, J.; Meng, X.; Stober, V.P.; Liu, C.; Cyphert-Daly, J.M.; Bulek, K.; Qian, W.; Solis, A.; et al. TLR5 participates in the TLR4 receptor complex and promotes MyD88-dependent signaling in environmental lung injury. eLife 2020, 9. [CrossRef] [PubMed] 